\title{
El libre comercio, peor que una plaga
}

\author{
Cecilia Chérrez*
}

Estados Unidos tomará el control del Amazonas para salvaguardar el agua y el oxígeno del planeta pues ahora está rodeado de países bárbaros que amenazan acabarlo.

(Párrafo extraído de un texto de geografía para estudiantes de sexto grado en Estados Unidos)

\section{Los últimos acontecimientos:}

El ALCA fracasa y la omc se debilita, pero...

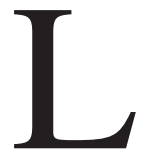

a última conferencia ministerial del ALCA, realizada en Miami a mediados de noviembre del año pasado, dejó el mensaje de que la estrategia de imponer la apertura de mercados y de servicios, acompañada de garantías a los derechos de propiedad intelectual y a las inversiones, así como una serie de reglas que favorecen intereses estratégicos de las grandes corporaciones transnacionales de Estados Unidos, puede mudar de presentación sin cambiar de contenido.

La impresión general es que el ALCA "ligth" sugerido e impulsado por Brasil desde julio y aprobado por los negociadores en la declaración final en Miami, si bien es un fracaso de la propuesta de Estados Unidos de iniciar el ALCA en enero del 2005, también provocó que este país saque una nueva carta: la decisión de negociar en cortísimo tiempo tratados bilaterales de libre comercio con los países andinos.

Esta iniciativa se suma a las negociaciones -extrañamente llamadas "bilaterales"- entre Estados Unidos y Centroamérica en bloque, sin Costa Rica, y a la suscripción ya realizada con Chile. Dos impresio-

\footnotetext{
* Coordinadora de la Campaña contra los Tratados de Libre Comercio de Acción Ecológica.
} 
nes saltan a la vista con este nuevo escenario: una es que los países del Mercosur y Venezuela quedan aparte, para los que Estados Unidos seguramente prepara otras iniciativas; y otra, tiene que ver con el hecho de que se ha lanzado una agenda compartida para Colombia, Ecuador, Perú y Bolivia, involucrando aspectos que no son estrictamente comerciales, sino más bien geopolíticos y de control del territorio.

Así pues, abordamos este artículo desde la amenaza de liberalización en un frente múltiple para nuestro país: por un lado, la imposición vertiginosa de firmar en corto tiempo un tratado bilateral con la mayor potencia militar, comercial y tecnológica del mundo; por otro, sostener las negociaciones de un muy disminuido ALCA que mantiene la fecha de suscripción para enero del próximo año; y, además, seguir con el proceso de liberalización en curso dentro de la Organización Mundial del Comercio, OMC, que sin embargo de que atraviesa momentos difíciles después del fracaso de su última cumbre ministerial, en Cancún, por el reclamo de 22 países exportadores agrícolas del Sur que exigieron la disminución de los abultados subsidios agrícolas del Norte, impidiéndole que incluya en su agenda los llamados "temas Singapur" (inversiones, competencia, compras de los gobiernos y facilitación del comercio), junta a la Unión Europea, UE, con Estados Unidos, en la presión sobre el Sur.

En todos los casos está en juego el control privado transnacional de los recursos naturales estratégicos como el petróleo y el gas, minerales, agua y biodiversidad, porque de ello depende cuáles empresas estarán en mejores condiciones de participar en la globalización

El secretario de relaciones internacionales de Estados Unidos, Colin Powell, es bastante claro cuando expresa: ... nuestro objetivo con el ALCA es garantizar a las empresas estadounidenses el control de un territorio que va del polo ártico hasta la Antártida, libre acceso sin ningún obstáculo o dificultad para nuestros productos, servicios, tecnología y capital en todo el hemisferio. Pretensiones con larga data, si se toma en cuenta que en 1912 el presidente de Estados Unidos de entonces, W. H. Taft, anticipó que "no es lejano el día en que tres (banderas con) estrellas y barras, en tres puntos equidistantes, marcarán nuestro territorio: una en el polo norte, otra en el canal de Panamá y la tercera en el polo sur. De hecho, todo el hemisferio será nuestro, como en virtud de nuestra superioridad de raza ya lo es moralmente"'.

1 En: "ALCA: ¿En el mercado confiamos?". Gerard Coffey. 2002. 
El parlamentario colombiano Jorge Enrique Robledo considerando el impacto jurídico e institucional de los tratados de libre comercio sostiene que, de firmarlos, la historia de América Latina quedará dividida en tres momentos: la colonización europea, la instauración de los sistemas republicanos, y la vigencia del ALCA (y otros tratados similares)"’2. La Asociación Americana de Juristas reconoce al sistema neoliberal y a sus herramientas principales, la OMC, el ALCA, el Fondo Monetario Internacional y el Banco Mundial como armas de destrucción masiva, en su informe presentado ante la comisión de derechos humanos de la ONU el 7 de abril del 2002.

\section{La letra menuda en el tratado bilateral Ecuador-Estados Unidos}

Los tratados bilaterales, impulsados intensamente durante el gobierno de Bush, le permiten a Estados Unidos mantener barreras proteccionistas en algunos sectores industriales e introducir nuevos mecanismos para enmascarar aranceles adicionales, como la ley contra el bioterrorismo. Este país ya ha suscrito 170 convenios de distinto tipo en un radio que prácticamente cubre todo el planeta, seleccionando a ciertos socios en cada región como pilares de sus intereses en cada continente: Singapur, Israel, Jordania, Australia ${ }^{3}$, o Chile, Centroamérica y cuatro países andinos en América Latina.

Sin embargo, lo que se cierne detrás de estas negociaciones tiene poco que ver exclusivamente con el comercio.

Según un artículo del Washington Post publicado en diciembre pasado, los impactos del TLC con Chile son mínimos para Estados Unidos: "este tipo de acuerdo es insignificante" se señala, considerando que el PIB de Estados Unidos aumentará en términos absolutos apenas

2 Jorge Enrique Robledo, senador de Colombia. En: Seminario Taller Parlamentario "Los acuerdos ambientales multilaterales: cómo son debilitados por los tratados de libre comercio". Quito, Mayo, 2003.

3 C. Katz. ALCA y Deuda, las dos caras de una dominación. Noviembre del 2003. En: "Algunos elementos sobre el Impacto en el sector agrícola ecuatoriano del TLC Ecuador-Estados Unidos". Patricio Ruiz. s/f. 
0,004\%. Con esta base, para Claudio Lara Cortez director de la revista Economía Crítica y Desarrollo ${ }^{4}$, si se sitúa este tratado bilateral en el contexto de las negociaciones del ALCA, nadie dudaría que este acuerdo bilateral tenía más que nada un interés político: cómo Chile podía aportar a la estrategia norteamericana para América Latina. Todo se reducía a convertir a Chile en país plataforma y jugar un rol divisionista en la región, a cambio de un poco más de acceso al mercado norteamericano.

Manuel Riesco, presidente del Consorcio Agrícola del Sur (CAS), de Chile, también afirma que "el tema de fondo de estos tratados es geopolítico y esto es lo que le interesa a Estados Unidos. La negociación del TLC EE.UU.- Chile estuvo mal hecha porque Estados Unidos no está pensando en vender cuatro camionetas más y Chile sí está pensando en vender cuatro racimos de uva más".

En el caso de Chile los grupos agro-mineros impulsaron el acuerdo porque construyeron nichos para sus productos en el mercado de ese país, igual cosa sucedió con compañías fruteras, pesqueras y madereras 5 .

En el caso del Ecuador el sector pesquero industrial y representantes del grupo El Juri han acompañado al grupo de negociadores, por lo que podría haber algún beneficio pactado para ellos, a cambio de renunciar a la protección de los otros sectores productivos. En todo caso, es significativo el hecho de que la cabeza del grupo de negociadores sea Mauricio Yépez, director del Banco Central, ex funcionario del FMI.

De todas maneras, el jefe de asuntos económicos de la embajada de Estados Unidos, Larry Memmot, en declaraciones a la prensa expresó que el tratado bilateral con Ecuador no es solo un convenio de interés comercial, sino también político.

\section{Algunas pistas}

Estados Unidos inició una campaña pública de presión al Ecuador para que cumpla un número de requisitos antes de sentarse a la mesa

\footnotetext{
4 "Las trampas del acuerdo entre Chile y EE.UU."

5 Informe de Patricio Ruiz.
} 
de negociación del TLC bilateral. A través de su embajadora en el país, Kristy Kenney, del jefe de la sección económica de esa misma embajada, Larry Memmott, y luego del Secretario de Estado Adjunto para asuntos de Economía y Negocios, Anthony Wayne, se exigió que "Ecuador resuelva sus problemas con empresas de Estados Unidos, como es el caso de la exoneración del IVA a la petrolera Occidental, además de Bellsouth, IBM y Duke Energy, antes de iniciar los diálogos. Con ello, se adelanta una señal clara respecto a los auspicios de alto nivel con los que contarán las empresas de Estados Unidos, que en términos de los tratados de libre comercio constan dentro de las garantías que se deben otorgar a los inversionistas extranjeros.

Esto, a pesar de que quienes tienen cuentas pendientes con el Ecuador son empresas de Estados Unidos, como Chevron-Texaco, que en estos momentos está siendo enjuiciada en el denominado Juicio del Siglo por la contaminación provocada en el norte de nuestra amazonia.

Al mismo tiempo, la embajadora presentó la demanda de que se haga una serie de cambios a nuestra legislación en el campo ambiental, de biodiversidad, propiedad intelectual, laboral y otros.

Esta presión, al igual que la anterior no cayó en saco roto, pero quienes le buscan respuesta en este caso no son funcionarios del gobierno sino un grupo de instituciones ambientalistas nacionales, socias de The Nature Conservancy institución ambientalista con base en Estados Unidos que definió una estrategia de presión al más alto nivel para que se apruebe una controvertida Ley de biodiversidad que promueve el control estratégico de las áreas ricas en biodiversidad por parte de organizaciones no gubernamentales e instituciones de investigación, la compra-venta de servicios ambientales, el ingreso de transgénicos, entre otras cosas.

\section{Yo te exijo, tú no me exiges...}

La arrogancia de Estados Unidos de exigir al Ecuador reformas legales como condición para negociar puede ser comparada (por oposición) con su negativa a hacer reformas legales frente a Chile. Durante la negociación del bilateral Estados Unidos-Chile, cuando este planteó la necesidad de una eliminación o revisión profunda de la aplicación de derechos anti-dumping, Estados Unidos le respondió que era imposible acordar cambios que signifiquen enmiendas a su legislación. 
"La ley anti-dumping de Estados Unidos es el instrumento legal más potente que tienen las industrias estadounidenses para protegerse de la competencia extranjera. La imposición de aranceles anti-dumping, que pueden exceder el 400 por ciento, puede excluir del mercado estadounidense, en forma eficaz, los productos de una firma extranjera", afirma el abogado William Perry, quien trabajó en la oficina de investigaciones anti-dumping del Departamento de Comercio de Estados Unidos y en la oficina del asesor jurídico de la Comisión de Comercio Internacional de ese mismo país. Y agrega: una orden anti-dumping puede tener una vigencia de 10 a 20 años, constituyendo lo que equivale a una barrera permanente a un producto específico de un país determinado.

Aproximadamente en el 90 por ciento de los casos elevados hasta 1997, el Departamento de Comercio falló que el exportador o productor extranjero practicaba dumping.

\section{¿En qué consiste el plan de Estados Unidos?}

El representante comercial de Estados Unidos, Robert Zoellick, presentó el 18 de noviembre del 2003 al Congreso de ese país una carta en la que describe las razones y los ámbitos de negociar un área de libre comercio con Colombia, Perú, ECUADOR y Bolivia.

"Nos permitirá resolver algunos impedimentos al comercio y a las inversiones, incluyendo una protección inadecuada de los derechos de propiedad intelectual, altos aranceles sobre productos agrícolas, un uso injustificado de medidas sanitarias y fitosanitarias, prácticas de permisos restrictivas, tratamiento discriminatorio a inversiones y limitaciones en el acceso por parte de los proveedores de servicios", dice Zoellick.

Afirma también que "existen importantes razones de política exterior y política comercial para tratar de incluir a los cuatro países en un área de libre comercio. Por más de una década, bajo diferentes Administraciones y Congresos, la política de Estados Unidos ha reconocido que una estrategia regional promoverá exitosamente nuestras metas de ayudar a los países andinos a combatir el narcotráfico, construir instituciones democráticas y promover el desarrollo socio-económico. El narcotráfico es un flagelo regional que no respeta fronteras. La experiencia ha demostrado que para combatirlo efectivamente se requiere de coordinación y 
estrategias efectivas entre los cuatro países andinos". Y más adelante señala: "necesitamos trabajar con Bolivia así como con Ecuador y los otros, en el desarrollo de las capacidades relativas a su habilidad para participar, implementar y aprovechar un acuerdo de este tipo".

La carta finaliza diciendo que "el área de libre comercio con los países andinos tomará en cuenta otros objetivos legítimos de Estados Unidos, incluyendo pero sin limitarse a la protección de la salud, la seguridad, el medio ambiente, la seguridad esencial y los intereses de los consumidores".

\section{Los 39 "objetivos específicos"}

La carta del representante comercial de Estados Unidos describe en su carta 39 objetivos ${ }^{6}$ para las negociaciones con los países andinos, a partir del segundo trimestre del 2004, los mismos que están agrupados en los siguientes ámbitos:

Comercio de bienes; comercio de servicios; inversiones; comercio electrónico;

aduanas, reglas de origen y cooperación para el cumplimiento de la ley; medidas sanitarias y fitosanitarias; barreras técnicas al comercio; derechos de propiedad intelectual; contratación pública; transparencia, anticorrupción, reforma reglamentaria; recursos comerciales; medio ambiente; trabajo; resolución de controversias entre estados.

Algunos de esos 39 puntos son:

. aumentar la venta de bienes y servicios,

- mantener un tiempo el cobro de aranceles cuando los productos andinos amenacen la industria de Estados Unidos,

. seguir aplicando mecanismos de retaliación,

. que los andinos protejan las patentes como lo hacen las leyes estadounidenses,

. eliminar las barreras sanitarias y fitosanitarias,

6 El Tiempo, Bogotá. 23 noviembre 2003. 
- eliminar las prácticas gubernamentales que perjudican las exportaciones de perecederos de Estados Unidos,

. desmontar las barreras administrativas aduaneras,

- el acceso total a textiles y ropa de Estados Unidos,

- que la resolución de disputas concuerde con las metas de la ley TPA (Trade Promotion Authority, Autoridad para la Promoción del Comercio) de Estados Unidos, lograda por Bush en el congreso de ese país para negociar directamente tratados de libre comercio,

- eliminar o reducir las barreras a la inversión estadounidense hasta que obtengan iguales derechos a los que tienen en su país,

. que los inversionistas de Estados Unidos sean tratados como si fueran inversionistas locales,

. comprometerse a apoyar la campaña de Estados Unidos en la OMC contra subsidios agrícolas y a mantener los programas estadounidenses de crédito a sus exportaciones,

. más ayuda en la implementación del acuerdo sobre medidas sanitarias y fitosanitarias de la OMC,

. que se promuevan políticas ambientales y comerciales que puedan ser respaldadas por todas las partes.

\section{Las presiones por una}

\section{Inaceptable ley de biodiversidad}

El 15 de enero de 2004 tuvo lugar una reunión ${ }^{7}$ en las oficinas de The Nature Conservancy, TNC, en Quito, entre varios representantes de ONGs ambientalistas "socias" de TNC, USAID y la embajada de Estados Unidos en el país.

Su objetivo fue definir una estrategia de cabildeo de alto nivel en la que se designen los roles y tareas de estas organizaciones con el fin de presionar al Ministro del Ambiente y a miembros del Parlamento Nacional para la aprobación en segundo debate de la ley de biodiversidad.

\footnotetext{
7 Ayuda Memoria de la reunión convocada por TNC a sus instituciones "socias", USAID y la Embajada de Estados Unidos en el Ecuador. CEDA. 16 de enero, 2004.
} 
Vale la pena preguntarnos cuál es el interés del gobierno de Estados Unidos en torno a nuestra biodiversidad. El proyecto de ley de biodiversidad objeto de la reunión entre las organizaciones mencionadas establece que:

(artículo 21) Corresponde al Ministerio del Ambiente planificar, coordinar, controlar y evaluar el manejo del sistema nacional de áreas naturales protegidas. El ministerio podrá contar con la participación de otras entidades del sector público, los pueblos indígenas, afroecuatorianos y comunidades locales, organizaciones no gubernamentales de conservación, e instituciones de investigación.

Posteriormente añade:

(artículo 29) El Ministerio del Ambiente podrá constituir derechos de uso y manejo sustentable sobre las áreas y los bienes y servicios del Patrimonio Nacional de Áreas Naturales a favor de entidades públicas, privadas o mixtas, a través de concesión, delegación y otras figuras legales, mediante concurso público, en función de los principios de esta ley.

De la lectura de estos artículos surge la preocupación de que posiblemente las organizaciones internacionales de conservación podrían estar interesadas en participar ya sea en la planificación, coordinación, control de estas áreas, o acceder a concesiones o delegaciones de bienes y servicios del Patrimonio de Áreas Protegidas.

Estados Unidos podría utilizar la figura del tratado bilateral para favorecer a sus ONGs de conservación e incluso a sus instituciones de investigación, ambos sectores con estrechos lazos con el sector empresarial privado.

Es importante mencionar que Estados no ha ratificado el Convenio de Biodiversidad, no es parte de él, pero paradójicamente apoya para que sus ONGs vengan al Ecuador a apoyarnos en la conservación de nuestras áreas protegidas.

El interés de estas ONGs de conservación no se limita al Ecuador. Aunque ellas no han presionado lo suficiente a sus gobiernos por la ratificación del Convenio mencionado, varias de estas transnacionales de conservación estadounidenses quieren participar en la implementación del Convenio de Biodiversidad, sobre todo en lo relacionado con áreas protegidas, en varias partes del mundo. 


\section{The nature conservancy:}

\section{Defensa ambiental y propiedad privada juntas ${ }^{8}$}

The Nature Conservancy fue fundada en 1951 y es sin duda una de las organizaciones conservacionistas más adineradas, con un presupuesto de $\$ 300$ millones de dólares por año.

Su misión es salvar las tierras ambientalmente valiosas a través de la propiedad privada. Busca trabajar de cerca con empresas para hacer coincidir los resultados ambientales con los negocios. Además de la filantropía de las corporaciones, estas se han convertido en "socias de la acción para la conservación" anunciando que minimizarán el uso de recursos ambientales o juntando su imagen a la de TNC, a manera de intento de elevar la reputación ambiental de la empresa.

Los ingresos de TNC se ven acrecentados por donaciones del gobierno de Estados Unidos: \$147 millones entre 1997-2001 y otros $\$ 142$ millones solo en el año 2000 por contratos o la venta de tierras al gobierno. TNC posee más de 36,9 millones de hectáreas de tierras en todo el mundo.

TNC acepta contribuciones para la compra de tierras y otras actividades, de parte de compañías tan destructivas del ambiente como la petrolera BP, General Motors, Orvis, MBNA, Centex House, Georgia Pacific Corp., 3M, Bank of America, Busch Entertainment, The Republic of Tea, the Home Depot, American Electric Power, Boeing, General Electric, Merril Lynch, Millstone Coffee. De éstas, varias están en el Directorio de TNC junto con Nasdaq, Stock Market, ConAgra Inc, Liberty Corporation, Procter and Gamble.

Con Chevron Texaco, la TNC estableció sociedad en un nuevo proyecto de unas 1000 hectáreas de bosque lluvioso en la costa sur de Brasil. Al anunciar esa sociedad, en septiembre del 2001, el vicepresidente de Texaco Brasil Exploration and Production, Antonio Correia de Pinho, dijo que "Texaco ha dado apoyo a TNC por más de diez años".

TNC estableció un Consejo de Líderes de la Conservación, CLC, cuyo presidente pertenece a American Electric Power (la genera-

\footnotetext{
8 Páginas web: nature.org; nationalcenter.org; chevrontexaco.com/news/archive/texaco/2001/2001/prg_4.asp;

george.loper.org/-george/trends/2003/May/1982.htm/.
} 
dora de electricidad más grande de EE.UU.). Otros miembros del CLC son General Motors, Georgia Pacific Corp, Southern Co., Internacional Paper, Exxon Mobil, BP Co., Centex and Dow Chemical.

\section{La ocupación y control de las áreas protegidas y la compra-venta de servicios ambientales}

La economía neoliberal ve a la naturaleza con una lógica de capital. Describe como "capital natural" al stock de materiales e información que existe en la naturaleza, y como "servicios ambientales" al flujo de materiales, energía e información del stock del capital natural combinado con capital humano o manufacturado para el bien humano (Costanza et al, 1998) ${ }^{9}$

Dentro de los territorios tradicionales de los pueblos indígenas y afroecuatorianos hay una serie de recursos naturales estratégicos para las empresas transnacionales y nacionales, como son el agua, el suelo, recursos no renovables, bosques, y biodiversidad, a los que quieren acceder. Los logros legales y constitucionales que los pueblos han alcanzado, constituyen un impedimento para asegurar este acceso. Por ello se han creado mecanismos de aparente ventaja para todos, los cuales conducen a que terceros (por ejemplo una empresa) tenga acceso a estos recursos a cambio de algún beneficio.

Según el proyecto de ley de biodiversidad, las delegaciones o concesiones del patrimonio natural del Ecuador a ONGs o empresas tienen que constar en el Registro de la Propiedad, por lo que estas ONGs o empresas pasarían a tener propiedad privada sobre las áreas entregadas por el Estado.

Además, se contempla que las áreas concesionadas puedan incluir nuevas áreas, es decir áreas de amortiguamiento y otras incluidas en las jurisdicciones municipales.

Cuando las tierras y áreas estén controladas por ONGs, ellas estarán en posibilidades de vender servicios ambientales con lo que las poblaciones locales se verán excluidas de sus tierras, por la fuerza, si hay conflicto o disputa, o pueden sufrir la expropiación de sus tierras. Es decir:

9 Alerta Verde 123 "Servicios Ambientales, el ciclo infernal". Acción Ecológica. Febrero, 2003. 
unos terceros (los que compran los servicios ambientales) adquirirán derechos sobre el área natural, la población local no podrá actuar soberanamente sobre sus espacios tradicionales porque "alteraría" las condiciones naturales sobre las cuales se transó la venta de servicios ambientales,la población local tendrá que pagar también por acceder a servicios ambientales que en esas condiciones de delegación o concesión pasaron a ser controlados por otros, ONGs o empresas, las poblaciones locales pueden verse obligados a migrar porque sus formas tradicionales de uso y manejo de los ecosistemas han sido cambiadas, o bien pueden ser violentamente desplazados por los nuevos interesados, el Estado perdería soberanía sobre el territorio.

\section{Cronología de las exigencias de EE.UU. sobre derechos de propiedad intelectual en el Ecuador}

Hasta antes de 1993, nuestro país excluía del patentamiento a los medicamentos, pero en ese año Estados Unidos presionó para que éstos se incluyan como materia patentable, además de las variedades vegetales y los procedimientos para su obtención, aunque excluyendo a los fármacos que figuren en la lista de medicamentos esenciales de la Organización Mundial de la Salud.

En 1998, ya como parte de la Organización Mundial del Comercio, OMC, el Ecuador modificó su legislación para responder a exigencias de las grandes corporaciones agro-alimentarias y farmacéuticas. Desde entonces, todos los productos farmacéuticos son objeto de patentes, se incluyó un estricto régimen de patentamiento de obtenciones vegetales (semillas) y se permitió el patentamiento de productos transgénicos a pesar de los muchos riesgos que pesan sobre la salud. De todas maneras, quedaron excluidas invenciones contrarias a la moral, el orden público y que puedan afectar al ambiente, como el genoma humano, las plantas y animales.

El anuncio de negociaciones de un tratado bilateral de libre comercio con Estados Unidos coincide con la exigencia al Ecuador de ciertos "requisitos pre-contractuales" como reformar otra vez sus normas sobre propiedad intelectual en el marco de lo que a Estados Unidos le parezca adecuado. En Estados Unidos las normas sobre propiedad intelectual han sido tan flexibles como para permitir a las empresas 
patentar la quinua, la sangre de drago, el yacón, la maca, la epibatidine (extraída de una rana bio-pirateada de los bosques del noroccidente del Ecuador), así como atentar contra la vida de millones de personas con VIH imposibilitados de acceder a medicinas genéricas más baratas que las inalcanzables controladas por un puñado de empresas farmacéuticas que reclaman el pago de regalías por sus patentes.

\section{La bioseguridad y la propiedad intelectual en la cuestionada ley de biodiversidad}

El proyecto de ley en cuestión permitiría el ingreso de transgénicos en nuestro sistema agrícola y el patentamiento de la vida.

Para Estados Unidos los convenios bilaterales son medios para homologar a su legislación las de otros países, tanto en materia sanitaria y fitosanitaria como de propiedad intelectual.

Las principales empresas productoras de tecnología y semillas transgénicas son de Estados Unidos. Una sola empresa estadounidense, Monsanto (hoy comprada por la farmacéutica Pharmacia) controló en el año 2000 el $94 \%$ del total del área sembrada con cultivos transgénicos a nivel mundial, y tiene una estrategia muy agresiva para extenderlos en los países aún sin adoptar esta tecnología. Apenas 5 países la han adoptado de manera masiva y unos 10 a nivel comercial.

\section{El Protocolo de Cartagena, un dolor de cabeza para Estados Unidos}

Estados Unidos no ha ratificado casi ningún acuerdo internacional en materia ambiental. El Protocolo de Cartagena sobre Bioseguridad (en vigencia desde el 11 de septiembre del 2003) no es una excepción. Este Protocolo internacional obliga a sus miembros a cumplir con una serie de obligaciones sobre el movimiento transfronterizo de transgénicos, así como en materia de etiquetado. Estados Unidos considera que estas medidas van a perjudicar económicamente a sus industrias.

Para los países que sí han ratificado el Protocolo de Cartagena, entre ellos el Ecuador, Estados Unidos diseñó un convenio bilateral interpretativo. El 29 de abril del 2003, funcionarios del Departamento de Agricultura de ese país se reunieron en las oficinas del Departamento de Estado para discutir temas relacionados con la implementación de algunos artículos del Protocolo. 
De esta reunión salió un documento diseñado como convenio bilateral marco que podría aplicarse a cualquier país, especialmente a países exportadores de transgénicos, pero también podría aplicarse a importadores (como el Ecuador).

La primera experiencia de aplicación de este convenio bilateral marco ya fue firmado por los países miembros del NAFTA/TLCAN el 29 de octubre del 2003.

\section{Propiedad intelectual sobre la biodiversidad}

En el campo de la biodiversidad se busca hacer posible el patentamiento a la vida y poder acceder a la riquísima biodiversidad del Ecuador, y beneficiar a su industria farmacéutica.

Son objetivos de EE.UU. sobre los Derechos de Propiedad Intelectual:

1. Que los países andinos y Ecuador en particular apliquen niveles de protección a la propiedad intelectual acordes con las leyes de Estados Unidos en esta materia.

2. Eliminar cualquier limitación a la patentabilidad, abriendo la posibilidad de que el genoma o sus partes pueda patentarse, así como cualquier planta medicinal de uso tradicional o alimenticia que aún no ha sido identificada por la taxonomía occidental, con fines estrictamente privados y económicos, impidiéndose su uso en el ámbito local o nacional, cobrando una regalía por utilizarla, y sin mediar consideraciones culturales, sociales o ambientales.

3. Proteger más estrictamente a las nuevas tecnologías.

Las negociaciones sobre Propiedad Intelectual en el ALCA incluyen de manera agresiva la "protección" a través de derechos de propiedad intelectual a las formas de vida. Aunque reconocer patentes de plantas es un absurdo, pues solo se pueden patentar las invenciones, se dan derechos exclusivos sobre organismos vivos, plantas, semillas, a través de patentes, derechos de obtentor (UPOV). Es decir, va más allá aún de las estipulaciones sobre propiedad intelectual de la OMC y es probable que este criterio sea trasladado a las negociaciones del TLC bilateral con Ecuador. 


\section{Implicaciones:}

- Introduce derechos monopólicos en el sistema alimentario.

- Limita el libre flujo de semillas.

- Aumenta la erosión genética y cultural.

- Impone regalías a los agricultores.

- Incrementa el precio de las semillas.

Serias implicaciones en la soberanía alimentaria:

- Orientación de la agricultura hacia un modelo biotecnológico.

- Implicaciones en la dirección que toma la investigación científica.

- Promoción del uso de semillas genéticamente modificadas, con todas las implicaciones de bioseguridad.

- El agricultor pierde control sobre un eslabón fundamental de la cadena productiva, como es la semilla, creando dependencia económica y tecnológica.

\section{Los negocios estrella de la globalización: la alimentación}

Para las grandes corporaciones agro-alimentarias como Cargill, Daniel Archer Midlands, Nestlé, resulta estratégico avanzar en el control de las fases productivas y de comercialización de gran parte de las provisiones alimentarias globales, como son ciertos cereales básicos (maíz, trigo, avena, soya, arroz) usados para el consumo humano directo o indirecto (cuando son usados para elaborar los balanceados que consume el ganado vacuno, porcino y aviar), además de leche, carnes, café, entre otros. Para lograrlo, requieren del cumplimiento de ciertos requisitos:

\section{La descampesinización}

El control corporativo de la alimentación no es posible mientras existan millones de pequeños y medianos productores agrícolas, campesinos, indígenas, en todo el mundo, muchos de ellos produciendo para el autoconsumo y utilizando todavía tecnologías tradicionales. Y si bien durante las últimas tres décadas la revolución verde desplegó grandes esfuerzos para incorporar, "integrar", a este sector en la agricultura 
moderna, muchísimos en la actualidad mantienen todavía viva su autonomía productiva, o, en no pocos casos, han entrado en procesos de recuperación de la diversidad agrícola inspirados por la defensa de la soberanía alimentaria como vía para romper la dependencia a la tecnología, insumos y alimentos controlados por las corporaciones.

Por eso, las reglas para la liberalización del comercio agrícola impulsado por Estados Unidos y sus agro-empresas multinacionales imponen un sistema de competencia desigual sobre el sector agrícola nacional, socavando la viabilidad de los pequeños productores pues son incapaces de competir con productos importados más baratos. En consecuencia millones de pequeños productores están siendo sacados de sus tierras, por lo que las reglas neoliberales para la agricultura se han constituido en el mas grande programa mundial de creación de refugiados, mientras asegura que las corporaciones globales controlen la agricultura.

Según el catedrático mexicano (de la Universidad Autónoma de México, UNAM) Andrés Barreda ${ }^{10}$, un requisito fundamental para el plan agrícola neoliberal es la descampesinización, pues ésta es una de las consecuencias más claras de la aplicación del Tratado de Libre Comercio para América del Norte (TLCAN/NAFTA) en su país, donde no pocos esfuerzos estatales se concentraron en crear desarraigo y provocar quiebras entre los pequeños productores agrícolas. Un ejemplo de esto es el programa Procede, basado en tres líneas de acción, salud, educación y alimentación, y que sirvió para desarrollar actividades como la manipulación reproductiva femenina, la pérdida de identidad entre las comunidades rurales, y la promoción de productos alimenticios industrializados. Más aún, en años en que por razones climáticas la producción de maíz mexicano estuvo en mejores condiciones frente al maíz estadounidense, el mismo gobierno mexicano cerró la frontera para impedir que salga maíz de este país hacia Estados Unidos. En la actualidad, hay 30 millones de mexicanos en Estados Unidos, muchos de los cuales son fruto de las políticas de expulsión de la gente del campo.

En los primeros ocho años de vigencia del Tratado, hasta el $2002^{11}$, ya se habían dejado de sembrar 1.6 millones de hectáreas de

\footnotetext{
10 Entrevista sobre "impactos del TLCAN", Quito, 14 de febrero, 2004.

11 "El círculo vicioso del TLCAN, La amarga experiencia mexicana en el agro". Víctor M. Quintana. 12 de junio, 2003.
} 
maíz, fréjol, trigo, arroz, soya y algodón. El abandono de tierra cultivable se profundizó en los Estados con mayor presencia de agricultura campesina tradicional, como Veracruz, Oaxaca, Guerrero, Morelos, Michoacán, Querétaro, Puebla y Guanajuato. En tanto, en las regiones con agricultura moderna, más tecnificada, como los Valles del Yaqui y Mayo, se ha disparado el rentismo de parcelas.

De 1994 al 2001 México elevó sus compras de productos agropecuarios y agroalimentarios extranjeros en $44 \%$. Por su parte, Estados Unidos elevó significativamente sus ventas a México. Así, México, uno de los grandes países agrícolas del mundo, ha puesto gran parte de su alimentación en manos extranjeras: importa el $95 \%$ de las oleaginosas que necesita; el $40 \%$ de la carne; el 30\% del maíz y el 50\% del arroz.

El maíz, el principal alimento de los mexicanos, provino de Estados Unidos en el 2001 en una cantidad igual a 6 millones 148 mil toneladas.

No se puede dejar de mencionar lo ocurrido en el Ecuador en los últimos años particularmente entre 1999-2002, período en el que ingresaron grandes cantidades de maíz, papas, café, a precios hasta más bajos del $50 \%$ del costo de producción, como sucedió con la papa y el café. En el caso del café, llegó a venderse a 1 dólar el quintal, provocando estragos dramáticos en la economía de caficultores nacionales, pequeños y medianos en su mayoría, que constataron que se trataba de una producción venida de Vietnam, donde se dio una sobreproducción tan alta que desplomó el precio. Este exceso de oferta fue el resultado de líneas de créditos facilitados desde hace varios años principalmente por el Banco Asiático de Desarrollo, y la distribución masiva de semillas de café de baja calidad, que también puso en crisis a productores en otros países, como Colombia y Brasil. La gran beneficiada de esta gran disponibilidad de café barato fue Nestlé, comercializadora que se esconde detrás de esta historia de agricultores que cayeron cautivos en los circuitos del monocultivo de alto rendimiento, la total orientación al mercado externo, y la dependencia al crédito y los insumos canalizados desde instituciones internacionales que responden a patrones productivos globales.

\section{Igualar las reglas para la agricultura}

Las reglas del Acuerdo de Agricultura de la OMC tienen el objetivo de liberalizar totalmente la circulación de productos agrícolas, redu- 
ciendo -hasta eliminar- las tasas arancelarias. En el texto que se discute en el ALCA sobre agricultura se señala que los términos que se negocien no podrán contradecir lo acordado en la OMC.

\section{Concentrar apoyos estatales en los grandes agricultores}

La agricultura de la globalización se sostiene también en el hecho de limitar al máximo el ya precario apoyo de los gobiernos a los pequeños y medianos propietarios agrícolas, con lo que pretende fortalecer aún más el poder de las agro-empresas orientadas a la exportación, facilitando de esta manera la concentración de la tierra en pocas manos

Un ejemplo muy claro se presenta en el propio Estados Unidos, donde la Ley Agrícola (Farm Bill) 2002 elevó a 248 mil 600 millones de dólares los subsidios a la agricultura estadounidense para los próximos diez años, principalmente a ocho cultivos: algodón, trigo, maíz, soya, arroz, cebada, avena y sorgo. Esto significa un aumento del $80 \%$ comparado con la Ley Agrícola anterior, de 1996.

Las dos terceras partes de los subsidios irán a los terratenientes más ricos, entre ellos 14 de los diputados que escribieron la Ley, y buscan favorecer a los grandes agro-negocios de Estados Unidos, dotando de las herramientas necesarias a los gigantes del comercio de granos y cereales como Archer Daniels Midland y Cargill, señala un estudio de la organización Institute for Food and Development de Estados Unidos, para que puedan capturar los mercados nacionales e internacionales. Es una ley que produce un efecto de Robin Hood invertido: roba a los más pobres para enriquecer a las transnacionales de la agricultura estadounidense.

El estudio señala también que los subsidios aprobados irán a manos de corporaciones como Wesbaco (un conglomerado de productos de papel), a Chevron Texaco, a la compañía de seguros John Hancock y a personas como Ted Turner (director ejecutivo de Time Warner Entertainment), a Dan Donalson, corresponsal del canal ABC y al multimillonario David Rockefeller del Chase Manhattan Bank, pero no a los agricultores familiares que actualmente apenas equivalen al dos por ciento de la población de ese país ${ }^{12}$.

12 En: "Magnates, beneficiados por los subsidios de EU". Juan Antonio Zúniga. La Jornada. México. 6 de enero, 2003.

164 
La UE por su parte, acaba de aprobar para el período 2003-2013 un presupuesto agrícola ${ }^{13}$ de 43 mil millones de euros. Esto significa, según un cálculo de la agencia de ayuda católica Cafod, que cada vaca en la Unión Europea recibe cada día aproximadamente 2.24 dólares; "cada vaca recibe más ingreso que la mitad de la población mundial", sostiene esta agencia.

Estos datos están en la base de la guerra de subsidios entre los dos grandes bloques del Norte, que llevan a los pequeños y medianos agricultores del

Sur a la quiebra, y buscan que desaparezcan como sector.

Entre los puntos exigidos por Estados Unidos dentro del tratado bilateral, consta el de "buscar un mecanismo con los países andinos que dará apoyo para alcanzar el objetivo de Estados Unidos en las negociaciones de la OMC para eliminar todos los subsidios a las exportaciones de productos agrícolas, al tiempo que se mantiene el derecho de brindar ayuda alimentaria legal y preservar el desarrollo del mercado agrícola de Estados Unidos y los programas de crédito a las exportaciones" ${ }^{14}$.

Dicho de otra manera, Estados Unidos cuenta con los andinos para dar la batalla contra la UE en materia de subsidios, en tanto mantiene e incrementa los suyos. El anzuelo, o premio consuelo, resultan ser realmente castigos, pues los programas de ayuda alimentaria, como lo señala un informe ${ }^{15}$ preparado y difundido por una ex funcionaria del Programa Mundial de Alimentos, dinamizan estratégicamente la colocación en el mercado internacional de la sobre-producción agrícola de Estados Unidos, también le permite ingresar en los países (sin inspecciones) los controvertidos productos transgénicos, competir en condiciones muy favorables con los productores domésticos, y generar dependencia a ciertos productos (como es el caso de la introducción de la soya en nuestro país, promocionada como fuente - superior de proteínas).

Ciertas disposiciones del ALCA debilitan la capacidad nacional de mantener reservas de alimentos para enfrentar emergencias, en esas condiciones el país receptor de la ayuda alimentaria queda expuesto al

\footnotetext{
13 Common Agricultural Policy.

14 Carta de Robert Zoellick, representante comercial de Estados Unidos, presentada ante el congreso de su país el 18 de noviembre del 2003.

15 Informe de Wilma Salgado. 2001.
} 
ingreso de productos de dudosa calidad, como se comprobó con la línea de crédito PL 480 extendida por Estados Unidos, que facilitó el ingreso de pasta de soya transgénica al Ecuador para los programas Mi Papilla y Mi Colada, para lactantes y madres embarazadas, lo que también fue comprobado en otros países andinos, centroamericanos y caribeños.

Otro aspecto preocupante con los transgénicos es que instituciones internacionales como el Codex Alimentarius, que en gran medida responde a las opiniones levantadas por las propias empresas agro-alimentarias, se ha pronunciado de manera ambigua respecto a los riesgos del consumo de transgénicos sobre la salud humana y el ambiente. Más aún, las disposiciones apuntan a que sean pruebas científicas las que confirmen esos riesgos. Con lo cual se contraría el fundamento mismo del Principio de Precaución que, por el contrario, exige que ante la existencia de sospecha de cualquier daño esta debe ser respondida con las pruebas científicas que la descarten. Si no lo hacen, la actividad (la difusión de transgénicos) debe ser suspendida.

\section{Crear dependencia al nuevo modelo agro-biotecnológico}

\section{- El caso de la soya}

Una vez que el modelo de producción de la "revolución verde", basado en el uso de agrotóxicos, fertilizantes, mecanización, da señales de agotamiento porque llegó a su techo y no consigue elevar más la productividad agrícola, el capitalismo ha iniciado un nuevo patrón tecnológico basado en la biotecnología, en la manipulación genética, como mecanismo para elevar la productividad de los vegetales y animales, y de esta manera aumentar la ganancia de las agroindustrias ${ }^{16}$.

Quizá el mejor ejemplo de aplicación del nuevo modelo constituye la Argentina soyera. Para el 2003, Argentina fue después de Estados Unidos el país de mayores desarrollos en el mundo de producciones originadas en semillas transgénicas. Solamente en soya transgénica se

\footnotetext{
16 Altamiro Borges y Joao Pedro Stedile. "Impactos del ALCA en la agricultura". Agosto 2002.
} 
sembraron en el 2001 y 2002 cerca de 13 millones de hectáreas cultivadas y en el 2003 los productores rurales usaron unos 150 millones de litros del herbicida Glifosato, de Monsanto. Argentina pasó a ser como nunca antes, insumo-dependiente.

Según el Grupo de Reflexión Rural ${ }^{17}$ el complejo de la soya basado en monocultivos de escala colosal y en una agricultura sin agricultores, sustenta un modelo de acumulación de capitales que se basa en la depredación del suelo y el avance sobre nuevos territorios. La producción y la comercialización de la soya descargan de ese modo sus costos sobre el medio ambiente, trasladándolos así a las generaciones futuras.

Los monocultivos de soya producen concentración de la propiedad de la tierra a la vez que expulsa a la población rural hacia las ciudades. Así mismo este complejo uniformiza las prácticas alimentarias y de salud de millones de seres humanos, bajo los dictados de las cadenas agro-alimentarias.

Hoy en Argentina se calcula que un 70\% de los alimentos industrializados contienen fuertes proporciones de soya transgénica, ya sea como harinas, como lecitina o como proteínas y aceites vegetales. De esta manera las corporaciones influyen en la vida de las personas a través de la publicidad y el alimento, haciéndolas perder la autonomía de sus conductas.

La economía de la soya modifica y limita las prácticas ciudadanas, sometiendo la democracia a intereses que subordinan las decisiones de los representantes del pueblo y que hacen primar decisiones "técnicas" adoptadas por organismos nacionales e internacionales que son siempre obedientes a los dictados de las grandes corporaciones. La soya en el mundo globalizado se ha convertido en un importante controlador social.

La instalación y expansión del complejo de la soya en Argentina ha provocado el agravamiento de la situación de catástrofe, con depredación extendida del suelo y de los recursos naturales, hambre, miseria, asistencialismo, insalubridad, colapsos urbanos, descapitalización, especulación financiera, desarraigo y extendidas migraciones, desigualdad social y una inseguridad sin precedentes.

17 GRR y AEDALT. "ALCA, modelo rural de exportación de insumos e indigencia y hambre para el grueso de la población argentina". Argentina. Febrero 2003. 


\section{La soya en Brasil: competitiva en base a destruir la biodiversidad}

Brasil incrementó su producción de soya en un $57 \%$ en los últimos 5 años, con lo que los países del Mercosur aumentaron el área de cultivo en cerca de 6 millones de hectáreas.

Según el análisis de Gerardo Evia, de Claes, Uruguay, estas cifras agresivas de expansión justo cuando el precio de la soya ha caído se explican por la competitividad del complejo soyero brasileño, que tiene los mayores rendimientos y los menores costos de producción, la principal ventaja en el caso de Brasil se encuentra en los bajísimos costos de la tierra.

De hecho, Brasil tiene una frontera agropecuaria abierta que se expande sobre áreas naturales y convierte grandes ecosistemas silvestres a la agricultura, generando un fuerte impacto ambiental y pérdida de biodiversidad. Por tanto el ambiente es la principal fuente de competitividad y la opción que se está tomando es "descontar capital natural" para competir con los subsidios. La tesorería de Estados Unidos ayuda con dólares y la de Brasil permite destruir biodiversidad ${ }^{18}$.

Esta potencialidad de poner nuevas tierras en producción equivalentes a las actualmente en uso en todo Estados Unidos es reconocida por el Departamento de Agricultura de ese país. También lo saben las empresas transnacionales agro-alimentarias como Cargill, Archer Daniels Midland y Bunge ${ }^{19}$, que juegan a dos puntas, pues en América del Sur el precio del glifosato es más bajo y existe una permisividad para que los productores guarden sus semillas sin pagar hasta ahora regalías.

Esto tiene que ver con la propuesta de largo plazo de convertir al Cono Sur en una cuenca soyera, con el impulso dado por el Banco Mundial, el cual desde 1989 identificó las tierras bajas bolivianas como un lugar privilegiado para el cultivo de soya. Desde ese mismo año Cargill cuenta con un puerto libre sobre el río Paraná que, con algunas mejoras, le permitirá sacar la soya boliviana. Y, por su parte, ACBL (American Commercial Barge Lines) se unió a Ultrapetrol S.A. para establecer un puerto en Morrinhos, en el estado de Matto Grosso, en el pantanal. Además, está el proyecto de la Hidrovía propuesto por el BID y el PNUD, para conectar el sistema de ríos que confluyen en la zona del

\footnotetext{
18 "ALCA, billetes y biodiversidad". Gerardo Evia. Uruguay. Noviembre, 2003. 19 Op. Cit. GRR Y AEDALT.
} 
Paraguay-Paraná-Uruguay y hacerlo navegable para embarcaciones de mayor calado.

\section{El rol de los Derechos de Propiedad Intelectual}

Vandana Shiva, eco-feminista y activista anti-globalización, sostiene que los Derechos de Propiedad Intelectual, junto a las reglas de comercio globales para la agricultura son fundamentalmente reglas para el robo, el secuestro económico de los recursos y el conocimiento de los pueblos del Sur para ponerlos en el mercado global, y se camuflan con la aritmética y las legalidades.

Con la aplicación de los Derechos de Propiedad Intelectual se pretende aplicar el control monopólico, a través de patentes y los derechos de obtentor, sobre todos los eslabones de la cadena agrícola y alimentaria a partir de la semilla, apuntando hacia el nuevo modelo de producción, basado en la biotecnología, en la manipulación genética, como mecanismo para elevar la productividad de los vegetales y animales, y de esta forma aumentar las ganancias de las agro-industrias, alterar y encarecer el patrón tecnológico de producción y reforzar la monopolización en el campo ${ }^{20}$.

\section{El campo mexicano, un espejo para mirarnos}

El Tratado de Libre Comercio para América del Norte, TLCAN, en vigencia desde 1994, muestra a la fecha las señales de desastre económico para el sector campesino e indígena de México. Por un lado, el ingreso masivo de productos agrícolas desde Estados Unidos, y por otro, la obligatoriedad de que se eliminen los apoyos internos a la agricultura mexicana, agravó más las condiciones en que fueron forzados a competir los pequeños productores agrícolas mexicanos con sus "pares" estadounidenses. Unos dos y medio millones de productores de maíz que ocupan el $57 \%$ de la superficie agrícola han tenido que vérselas con la

20 "Impactos del ALCA en la agricultura". Altamiro Borges y Joao Pedro Stedile. Brasil. 2002. 
inundación de este grano llegado desde Estados Unidos a un precio 20 por ciento por debajo del costo de producción ${ }^{21}$.

Después de una década de aplicación del tratado de libre comercio en Norteamérica los precios reales de los productos del campo se han desplomado y paradójicamente los precios de venta de los alimentos se han elevado a niveles dramáticos. Según algunos cálculos, el precio de la canasta familiar aumentó en ese lapso 506 por ciento ${ }^{22}$.

El caso del maíz es el mejor ejemplo, ya que entre 1994 y el 2000 la producción mexicana de este grano disminuyó en 3.7 por ciento, y las importaciones aumentaron 135.7 por ciento. Su precio de garantía para los campesinos mexicanos disminuyó 43.4 por ciento y el consumidor que compró tortillas, parte esencial de la dieta básica mexicana, vio elevar su precio en 571 por ciento. Otro ejemplo es el del frijol, cuya producción entre 1994 y el 2002 cayó 5.8 por ciento, sus importaciones se elevaron 28.6 por ciento y el costo al consumidor se incrementó 373 por ciento. El caso del arroz es similar, en este lapso la producción interna descendió 35.4 por ciento, su precio de garantía disminuyó 43.3 por ciento, las importaciones aumentaron 141 por ciento y el costo al consumidor final se disparó en 264.5 por ciento.

Con base en estos datos, Laura Juárez, investigadora de la Universidad Obrera de México, afirma que su país tiene con Estados Unidos el tratado comercial más desventajoso del mundo. Por más plazos de desgravación que se den, por más salvaguardas que se apliquen, subsidios que se otorguen, renegociaciones o suspensiones que se logren, la competencia con Estados Unidos "está perdida desde el principio".

Las profundas asimetrías entre los dos países no son un mito: Estados Unidos posee tecnología de punta, protege a su sector agrícola de la competencia externa, cuenta con mano de obra barata e ilegal que le disminuye los costos, es productor hegemónico de alimentos estratégicos, cuenta con subsidios elevados, impone su patrón alimentario al resto del mundo y manipula los precios de los productos. Las transnacionales de Estados Unidos tienen la hegemonía en la competencia por el

\footnotetext{
21 Ibid.

22 EI ABC del ALCA. Fundación Solón. Bolivia. Mayo 2002.

170
} 
predominio del mercado global en diversos sectores, como el de alimentos, aún por encima de la Unión Europea y Canadá23.

La identificación de las distintas claves de esa asimetría, que le han garantizado a Estados Unidos ganar frente a sus "socios" comerciales, es de importancia vital para el resto de países latinoamericanos. Si partimos del hecho de que para todo país es indispensable defender su soberanía alimentaria y energética, además de la soberanía jurídica y política, es obvio que los tratados internacionales que suscriba no deben interferir en tales objetivos.

\section{Los impactos por erosión genética}

La comercialización mundial de maíz está basada en apenas 4 variedades, y por lo tanto desencadena erosión genética, es decir provoca la disminución acelerada de variedades locales: el 73 por ciento de la producción mundial proviene de la variedad Dent, utilizada para alimento de ganado y obtención de aceite, almidón, alcohol, jarabes; las otras tres variedades son: Flint, que tiene tolerancia al frío y resiste condiciones pobres de almacenamiento, Fluor, usada para consumo humano, y Pop, o reventador. ${ }^{24}$

Los 41 complejos raciales de maíz y las miles de variedades que posee México, ya dan señales evidentes de erosión genética a partir de la inclusión del maíz en las negociaciones del TLCAN con el argumento de que los productores mexicanos son ineficientes pues el rendimiento de ese cultivo a nivel nacional ha permanecido tradicionalmente por debajo de las 2 toneladas por hectárea, mientras la producción en Estados Unidos es de 10-12 toneladas por hectárea.

Este argumento no consideró que las variedades locales mexicanas se desempeñan mejor que las mejores semillas híbridas de Estados Unidos en la mayoría de los ambientes en los que se siembra maíz en México, tampoco consideró que el germoplasma mexicano posee características excepcionales de resistencia a las heladas y al granizo, a plagas y enfermedades y tiene enorme adaptabilidad, ni tomó en cuenta los

23 Artículo de Patricia Muñoz publicado en La Jornada. México. 19 de abril 2003.

24 "Impactos del comercio de transgénicos: un caso de deuda ecológica". Elizabeth Bravo. Noviembre 2001. 
severos impactos ambientales de la producción de maíz en el país del norte ${ }^{25}$.

\section{La contaminación genética y los derechos de Propiedad Intelectual}

Según los acuerdos del TLCAN, México, por ser centro de origen del maíz, logró formalmente proteger su producción de maíz con aranceles que se eliminarían paulatinamente en un período de 15 años; sin embargo, durante los 7 primeros años de vigencia del tratado el gobierno permitió que las importaciones de maíz realizadas por Cargill, Monsanto y Continental, dedicadas a la producción de transgénicos y agrotóxicos, sobrepasen las cuotas fijadas sin cobrar los aranceles previstos.

En Estados Unidos hay unas 140 millones de hectáreas sembradas con maíz, de las cuales al menos el 20 por ciento (unos 28 millones de hectáreas) corresponde a maíz transgénico, que no es clasificado y se mezcla con las otras variedades, antes de su comercialización en el mercado doméstico y en el internacional. Esto provocó que al cabo de unos años se haya producido contaminación genética del maíz mexicano, detectada en Oaxaca por la universidad de Berkeley y la Unión Zapoteca-Chinatega, y confirmada en septiembre del 2001 por la secretaría de Medio Ambiente y Recursos Naturales de ese país ${ }^{26}$.

Sin embargo, el alcance de los derechos de propiedad intelectual ha otorgado prebendas tan grandes a las empresas que no son pocos los casos de agricultores enjuiciados por estas empresas por el uso gratuito de sus semillas, cuando en realidad fueron contaminados...

En Canadá y en Estados Unidos, Monsanto y Cargill, han recurrido a juicios en miles de ocasiones para reivindicar la propiedad intelectual de cultivos contaminados por sus semillas transgénicas. El agricultor canadiense Percy Schnider, quien participó en octubre del 2002 de las jornadas sociales de lucha contra el ALCA que se desarrollaron en Quito, relató su propia experiencia: su cultivo de colza fue contaminado

\footnotetext{
25 Alejandro Nadal. México. 2000.

26 "ALCA, modelo rural de exportación de insumos e indigencia y hambre para el grueso de la población argentina". Grupo de Reflexión Rural y Red por una A. Latina Libre de Transgénicos.

172
} 
con material transgénico de la granja de su vecino, a partir de semillas transgénicas patentadas por Monsanto. Cuando la empresa encontró el material transgénico lo enjuició. Su cultivo de colza ahora pertenece a Monsanto, y debido a que los genes permanecen en el ambiente, ya no puede volver a sembrar colza. El juicio con la empresa continúa.

Otro caso ilustrativo de las pretensiones jurídicas de las empresas agro-alimentarias ante las regulaciones y las leyes de protección ambiental y de la salud pública es el relacionado con la comercialización del maíz transgénico conocido con el nombre de Starlink. Este maíz tiene la toxina Cry9C y fue aprobado por la Agencia de Protección Ambiental, EPA, de Estados Unidos, solo para consumo animal considerando los riesgos de alergias de darse el consumo humano. La reguladora también exigió a Aventis, la empresa productora de Starlink, que este maíz no podía llegar a los consumidores humanos a través de la carne de los animales alimentados con este.

Aventis apeló esta decisión de la EPA y al mismo tiempo puso el maíz en el mercado. A mediados del 2000 la organización Amigos de la Tierra encontró el maíz Starlink en muchos productos hechos a base de maíz, y no solo dentro de Estados Unidos. La primera evidencia se encontró en las tortillas para tacos de Taco Bell (Eichenwald, 2000). Sin embargo, es posible que el polen de este maíz se haya diseminado hacia variedades convencionales, pues se constató en algunas partes que a pesar de que el tipo Starlink ocupó solo 1\% de la superficie, contaminó el $50 \%$ de la cosecha total. Varios agricultores que no sembraron este maíz, sufrieron de todas maneras contaminación ${ }^{27}$.

\section{La energía y el agua}

La nueva política energética de Estados Unidos, lanzada en mayo del 2001 parte de reconocer el hecho de que ese año ese país enfrentaba la más seria escasez de energía desde comienzos de los años '70. Esto está en la base de la especial atención dada por el gobierno de Bush para "construir una asociación energética sólida e interdependien-

27 Op. Cit. Elizabeth Bravo. 
te en las Américas" para garantizar una "seguridad energética común" que asegure un acceso adecuado y confiable a la energía ${ }^{28}$.

Sin embargo, este ha sido un objetivo histórico de Estados Unidos en sus relaciones con América Latina. Aunque en Medio Oriente, donde se ubican dos terceras partes de las reservas petroleras mundiales, cada uno de los grandes bloques económicos en gestación trata de diversificar las fuentes de suministros petroleros y de gas, dando especial atención a las cuencas petroleras y gasíferas localizadas en sus respectivas áreas geográficas de mayor influencia.

En las últimas décadas se fue convirtiendo a América Latina en exportadora neta de hidrocarburos; aquí se localiza el 11 por ciento de las reservas mundiales de petróleo y se produce cerca del 15 por ciento del crudo que se extrae a nivel internacional; cuenta con el 6 por ciento de las reservas internacionales de gas natural, reservas de carbón mineral suficientes para más de dos siglos de explotación y recursos para la hidroenergía de la que cuenta con casi 23 por ciento del potencial mun$\operatorname{dial}^{29}$

Mientras las reservas petroleras de Estados Unidos alcanzarían para unos diez años, a los niveles de extracción de los últimos años, Latinoamérica cuenta con reservas para más de 30 años. A la fecha, la región ya provee a Estados Unidos cerca del 40 por ciento del petróleo que utiliza, que sumado al 15 por ciento que le viene de Canadá, el continente es surtidor de más de la mitad de su demanda.

Según datos del PNUD, los irracionales patrones de consumo de energía en Estados Unidos superan las ocho toneladas anuales de petróleo per cápita. Sin embargo, la causa de la crisis energética no se la identifica en el ámbito del despilfarro sino en una insuficiente oferta. El incremento de la oferta energética a partir de combustibles convencionales (petróleo, gas y carbón) es uno de los objetivos fundamentales de la política energética de Estados Unidos. Con ello, solo empeorará los niveles de emisiones de $\mathrm{CO}_{2}$ de este país, que ya bordea el 25 por ciento, con apenas el $4.7 \%$ de la población mundial.

\footnotetext{
28 "Energía y medio ambiente en las negociaciones del ALCA", Ramón Pichís Madruga. Cuba. s/f.

29 BP-Amoco. 2000; OLADE. 2000.
}

174 
En cuanto al agua dulce, el escenario no cambia. Tratándose de un recurso escaso, por los niveles de contaminación provocados durante las últimas décadas y la pérdida creciente de fuentes de aprovisionamiento a causa de los estragos del cambio climático (incluso se ha puesto plazo de 15 años a los glaciares de los nevados del Ecuador), el control del agua es absolutamente estratégico.

A diferencia de lo analizado respecto al petróleo, Estados Unidos cuenta con suficiente potencial de agua, superior a la media mundial; sin embargo la situación de carestía que se va imponiendo en muchas regiones hacen prever a las empresas la rentabilidad de un gran negocio basado en la entrega de una "mercancía", vital como escasa.

Estados Unidos está rodeado regionalmente de agua: Canadá posee diez veces la disponibilidad de agua de Estados Unidos, y América Latina y el Caribe casi cuatro veces. Aun cuando las mayores empresas del agua, aquellas que han ido aprovechando la implantación de políticas de privatización, son en su mayoría de origen europeo (Vivendi, Suez Lyonnaise) las inversiones de Estados Unidos en este sector no son pequeñas.

Para Andrés Barreda, los planes ${ }^{30}$ de la Integración de la Infraestructura Regional para Sudamérica, IIRSA ${ }^{31}$, incluyen un tejido de vías, líneas férreas, puertos fluviales y marítimos, redes de comunicación con fibra óptica, que constituyen un entramado de corredores multimodales diseñados para facilitar la exploración y explotación de recursos naturales estratégicos, así como el control de territorios con fines políticos, militares, que complementan y apoyan la agenda económica de la globalización.

Parte de esa infraestructura, diseñada por el BID y apoyada por CEPAL y la CAF, va construyéndose actualmente alrededor de la Amazonía, como una herradura que, sin embargo, no solo mira a la cuenca sino además enlaza zonas de yacimientos petroleros y mineros, y bordea el pie de monte andino, donde las cuencas altas de los ríos, con su agua limpia, están más a la mano...

Otro indicio significativo es lo que ocurre con el gigantesco acuífero Guaraní, quizá la reserva de agua dulce más grande a nivel mun-

\footnotetext{
30 "Sentido y origen del ALCA". México. Enero, 2004.

31 www.ilisa.org
} 
dial, que se extiende por las cuencas de los ríos Paraná, Paraguay y Uruguay, en una superficie de 1'194.000 kilómetros cuadrados, repartidos entre cuatro países, Brasil, Paraguay, Uruguay y Argentina. Sobre la zona conocida como "la triple frontera", donde se encuentra el acuífero, pesa la presión de Estados Unidos para que los gobiernos circundantes ejerzan un mayor control pues allí se encontrarían células dormidas de terroristas internacionales y actividades de narcolavado ${ }^{32}$.

Giancarlo Delgado Ramos ${ }^{33}$ sostiene que de lo que se está hablando es de "moldear las legislaciones nacionales de los países sudamericanos para que faciliten programas de inversión privada sobre un recurso por demás estratégico. Como prueba, el 22 de mayo del 2003 se reunieron en Montevideo el Banco Mundial y los países del MERCOSUR para firmar el Proyecto de Protección Ambiental y Desarrollo Sustentable del Sistema Acuífero Guaraní. Los fondos vendrán del GEF, con dinero de Estados Unidos; la OEA será la oficina regional de ejecución, además del BM. Además del GEF también tendrá fondos de la Agencia Internacional de Energía Atómica, Vigilancia Geológica Germana y el Programa del Agua de los Países Bajos. Documentos del BM consideran especialmente el potencial geotérmico para la generación de energía eléctrica. Añade Delgado Ramos que las fases propuestas por el Banco Mundial revelan las intenciones con el acuífero: por un lado impulsa una concentración del manejo de cuencas hídricas en manos de "selectos actores" y una vez consolidados, busca, por otro lado, colocar a las multinacionales de los países donantes en el centro de la gestión y usufructo del agua (servicios hídricos de almacenaje, distribución, potabilización, generación de termo e hidroelectricidad, etc.)

Este usufructo privado del agua se consolida a través de concesiones parciales o totales a favor de multinacionales como Monsanto Wells y Bechtel, de Estados Unidos, las francesas Suez/división Ondeo (antes Lyonnaise des Eaux) y Vivendi, las españolas Aguas de Valencia y Unión FENOSA ACEX, o la inglesa Thames Water. Proceso posible desde que "los gobiernos están abandonando el control de las fuentes nacionales de agua al participar en tratados comerciales tipo OMC,

\footnotetext{
32 "El peligro terrorista en la Triple Frontera hace agua", Fernando Glenza. Revista Koeyu. Argentina. Febrero, 2004.

33 "Banco Mundial y desnacionalización integral de México". UNAM. México. 2003. en: Op. Cit. Fernando Glenza.

176
} 
ALCA, con lo que transfieren la gestión de los recursos hídricos hacia la iniciativa privada", dice Giancarlo Delgado.

El informe de Fernando Glenza describe otro proyecto en la Cuenca del Plata, "Desarrollo de una Agenda de Investigación Multidisciplinaria en la cuenca del Plata", financiado por la National Science Foundation de Estados Unidos, y consta dentro del Directorio de Programas Internacionales de la Asociación Americana para el Avance de la Ciencia, AAAS, con financiamiento de Rockefeller, Ford, IBM, Kellogg, Kodak, Coca Cola, todas empresas de Estados Unidos y vinculadas a un enorme consumo de agua. Su objetivo es, al igual que en el caso del acuífero Guaraní, consolidar el "sistema de información geográfica" más preciso de la región, y poder de esta manera "enlazar" iniciativas ya existentes del BM, del BID. (www.aaas.org).

\section{El "corazón" del libre comercio: Los derechos del inversionista}

El abogado canadiense en asuntos comerciales Barry Appleton ilustró el enorme poder que las reglas comerciales otorgan a las empresas transnacionales con este ejemplo: "podrían condimentar la comida de los niños con plutonio líquido; si se lo prohíbe y la empresa productora es estadounidense, habrá que pagarle una indemnización"34.

El poder jurídico que los tratados de libre comercio otorgan al inversionista extranjero es el corazón de la agenda neoliberal. Después de la derrota provocada al Acuerdo Multilateral de Inversiones, donde se hacía constar la relación inversionista-estado en términos muy favorables a las empresas, a pesar de que ellas no son signatarias del tratado, adquiriendo por ejemplo la capacidad de desafiar las leyes, políticas y prácticas de los gobiernos que no son el suyo propio. Este principio pasó al TLCAN, incorporado en su artículo 111, con el cual quedó aplicado el derecho del inversionista para enjuiciar a un gobierno por ganancias actuales y futuras pérdidas a raíz de acciones (basadas en legislación laboral, ambiental, etc.) de ese gobierno. El derecho de las empresas a

34 "El ALCA y la amenaza para los programas sociales, la sostenibilidad ambiental y la justicia social en las Américas". Maude Barlow. Canadá. s/f. 
entablar un juicio contra un gobierno y exigir pruebas concretas de que sus operaciones o productos sí causan daño va en contra del Principio de Precaución consagrado en la Declaración de Rio (1992) que admite la necesidad de tomar decisiones legislativas y normativas sin contar con pruebas absolutas de que un proceso o sustancia esté provocando serios daños en el ambiente ${ }^{35}$.

\section{Hay varios ejemplos de que esto no es una interpretación exagerada.}

Un ejemplo ilustrativo es el caso de la empresa Ethyl Corp. de Virginia que obligó al gobierno canadiense a revocar la legislación que prohibía la venta transfronteriza de su producto, el aditivo para gasolina MMT, que ha sido prohibido en muchos países, y exigió una indemnización por las ganancias no percibidas.

Otro ejemplo es el de la empresa estadounidense Metalclad, con expectativa de disponer desechos tóxicos de su país de origen en la ciudad de Guadalcázar, en el estado mexicano de San Luis de Potosí, igualmente demandó una indemnización de 16 millones de dólares cuando por razones ambientales el gobierno estadual decidió parar esas operaciones.

En estos momentos se halla en curso una demanda de 16 millones de dólares de parte de la empresa petrolera Harken, de propiedad del presidente Bush, contra el gobierno de Costa Rica, por declarar una moratoria a la ampliación de la frontera petrolera en zonas de interés de esta empresa.

La empresa californiana Sun Belt Water Inc., de exportación de agua, enjuició al gobierno canadiense por 14000 millones de dólares por prohibir la exportación de agua en grandes cantidades en $1993^{36}$.

Y un caso más cercano: Cochabamba, la tercera ciudad de Bolivia, después de privatizar los servicios de agua por presión del FMI y el Banco Mundial, sufrió un alza escandalosa en las tarifas por decisión de la concesionaria Aguas del Tunari, nombre adoptado por la empresa Bechtel de Estados Unidos. Tras la cancelación del acuerdo, resultado de la "guerra del agua" que se desató en esta ciudad por los costos del agua, Bechtel demandó a ese país 30 millones de dólares como compensación.

\footnotetext{
35 Gerard Coffey. Op. Cit.

36 Maude Barlow. Op. Cit.
} 
El tribunal para este caso se instaló en un programa poco conocido del Banco Mundial, el Centro Internacional para la presentación de Disputas sobre Inversiones, y quien seleccionó al presidente de este tribunal fue James Wolfensohn presidente del Banco Mundial, señalando la falta de independencia y objetividad de este procedimiento ${ }^{37}$, y el impacto de estos enjuiciamientos no sólo es económico. La sola posibilidad de estas represalias retraerá aún más la voluntad política de los gobiernos para decisiones a favor de los derechos humanos o la protección ambiental. Exactamente como lo exige el libre comercio. 
